\title{
Operation analysis of primary and secondary networks of distributed solar heating system in Tibet
}

\author{
Chengpeng Liu ${ }^{\text {a }}$ \\ Tibet Autonomous Region Energy Research Demonstration Center, Lasa 850000, China
}

\begin{abstract}
Tibet is located in a high cold and high altitude area. Heating in winter is an important problem to be solved urgently, and the distributed solar heating system provides a solution for the efficient and clean utilization of energy in this area. Through the test and commissioning of the distributed solar heating system with supplementary combustion in Tibet, the operation characteristics of the heating system are analyzed from the temperature changes of the primary network and the secondary network. The research results can provide technical support for the application and promotion of the solar distributed heating system with supplementary combustion in Tibet.
\end{abstract}

Keywords: Solar energy; Heating; Supplementary combustion; Distributed energy

\section{Introduction}

Limited by the lack of fossil fuel resources and the fragile ecological environment, it is impossible to establish a large-scale coal-fired power station with cogeneration for heating, which restricts the heating mode of residents in Tibet [1-3]. Tibet is extremely rich in solar energy, with an average annual radiation of $6000 \sim 8000 \mathrm{MJ} / \mathrm{m} 2$, an average annual sunshine of about $3000 \mathrm{~h}$ and high stability $[4,5]$. As an important part of the future energy structure, solar energy is mainly used in photovoltaic power generation and solar heat utilization. Solar heating is a green heating method that uses solar radiant energy as a heat source, which not only saves resources but also meets the requirements of environmental protection [6,7]. However, solar energy has the characteristics of instability and intermittence, and can not meet the heating needs of users in special weather $[8,9]$. Therefore, it is the best choice to adopt multi energy complementary heating mode to form the heating source of Tibet Autonomous Region from the technical and economic aspects [10]. The solar heating system in Tibet is selected in this research. Distributed solar heating can effectively improve the solar assurance rate, and auxiliary heat sources such as gas wall mounted furnace can overcome the disadvantage of discontinuous solar energy and realize the continuous and stable heating of Tibetan residents in winter [11,12]. In this paper, combined with the supplementary combustion solar distributed heating system in Tibet, the heating commissioning test is carried out, and the operation of the system is analyzed from the daily temperature changes of primary network and secondary network, which provides technical support for the popularization and application of the system in Tibet.

\section{Integration of heating system}

\subsection{Introduction to the system}

Take the heating of the office building of the energy research and demonstration center of the Tibet Autonomous Region as an example, build a solar heating system with supplementary combustion with a heating area of no less than $570 \mathrm{~m} 2$, and the solar energy utilization rate is no less than $70 \%$. The solar distributed heating system with supplementary combustion takes solar energy as the main heat source and gas as the auxiliary heat source. Natural gas can provide heat source support for the system when solar energy does not meet the demand. It is the best coupling mode of solar energy and gas $[13,14]$. At the same time, the hot water storage tank can not only solve the problem of energy peak and valley, but also reduce conventional energy consumption and protect the environment $[15,16]$. The working principle of the system is shown in Figure 1.

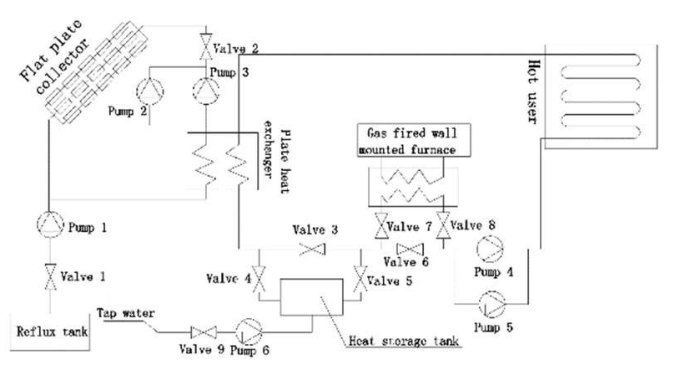

Fig. 1 Working principle of solar distributed heating system with supplementary combustion 


\subsection{Main equipment}

\section{a) Flat plate collector}

In the solar heating system, the flat plate collector is placed at a certain angle, and the sunlight passes through the cover plate and incident on the heat absorbing plate coated with selective coating, in which the heat absorbing plate collects most of the radiant energy and converts it into heat energy. 15 large flat plates and 3 small flat plates of two thicknesses are selected for the system. The main technical parameters of large and small flat plate collectors are shown in Tables 1 and 2.

Tab.1 Technical parameters of large flat plate collector

\begin{tabular}{|c|c|}
\hline Parameter $/$ Unit & Numerical value \\
\hline Total area $/ \mathrm{m}^{2}$ & 13.17 \\
\hline Daylighting area $/ \mathrm{m}^{2}$ & 12.35 \\
\hline Heat absorber area $/ \mathrm{m}^{2}$ & 12.37 \\
\hline Medium content $/ \mathrm{L}$ & 11.35 \\
\hline Maximum pressure $/$ bar & 10 \\
\hline Air drying temperature $/{ }^{\circ} \mathrm{C}$ & 218 \\
\hline Geometric dimension $/ \mathrm{mm}$ & $5920 * 2224 * 135$ \\
\hline $\begin{array}{c}\text { Recommended working } \\
\text { flow } /\left(\mathrm{L} \cdot \mathrm{m}^{-2} \cdot \mathrm{h}^{-1}\right)\end{array}$ & $10-25$ \\
\hline
\end{tabular}

Tab.2 Technical parameters of small flat plate collector

\begin{tabular}{|c|c|c|}
\hline $\begin{array}{c}\text { Parameter / } \\
\text { Unit }\end{array}$ & \multicolumn{2}{|c|}{ Numerical value } \\
\hline $\begin{array}{c}\text { National } \\
\text { standard } \\
\text { model }\end{array}$ & $\begin{array}{c}\text { P-G/0.6L/LM- } \\
1.84\end{array}$ & $\begin{array}{c}\text { P-G/0.6L/LM- } \\
1.76\end{array}$ \\
\hline $\begin{array}{c}\text { Total area / } \\
\mathrm{m}^{2}\end{array}$ & 2 & 2 \\
\hline $\begin{array}{c}\text { Daylighting } \\
\text { area / } \mathrm{m}^{2}\end{array}$ & 1.84 & 1.76 \\
\hline $\begin{array}{c}\text { Core volume } \\
/ \mathrm{L}\end{array}$ & 1.5 & 1.5 \\
\hline $\begin{array}{c}\text { Maximum } \\
\text { pressure / } \\
\mathrm{MPa}\end{array}$ & 0.6 & 0.6 \\
\hline $\begin{array}{c}\text { Air drying } \\
\text { temperature } \\
/{ }^{\circ} \mathrm{C}\end{array}$ & 218 & 218 \\
\hline $\begin{array}{c}\text { Geometric } \\
\text { dimension } / \\
\text { mm }\end{array}$ & $2000 * 1000 * 80$ & $2000^{*} 1000 * 120$ \\
\hline
\end{tabular}

\section{b) Heat storage tank}

In the process of solar energy utilization, heat storage is mainly to make up for the impact of solar energy discontinuity and convert the absorbed solar radiation energy into heat energy for storage. A vertical cylindrical pressure heat storage tank is selected for the system, and its technical parameters are shown in Table 3.
Tab.3 Technical parameters of heat storage tank

\begin{tabular}{|c|c|}
\hline Parameter / Unit & Numerical value \\
\hline Design pressure / MPa & 0.33 \\
\hline $\begin{array}{c}\text { Pressure of pressure test } / \\
\mathrm{MPa}\end{array}$ & 0.42 \\
\hline Design temperature $/{ }^{\circ} \mathrm{C}$ & 90 \\
\hline Volume $/ \mathrm{m}^{3}$ & 8.5 \\
\hline Working medium & Water \\
\hline Main material & Q245R \\
\hline Product standard & GB150 \\
\hline
\end{tabular}

c) Wall mounted gas boiler

Two LN1GBQ50-NCN52HD condensing gas wall mounted furnaces are selected as auxiliary heat sources for the system, and their main technical parameters are shown in Table 4.

Tab.4 Technical parameters of gas wall mounted furnace

\begin{tabular}{|c|c|}
\hline Parameter / Unit & Numerical value \\
\hline Rated voltage / V & 220 \\
\hline Frequency / Hz & 50 \\
\hline Rated gas pressure / Pa & 2000 \\
\hline Rated heat output / kW \\
\hline $\begin{array}{c}\text { Rated condensation heat } \\
\text { output / kW }\end{array}$ & 57.7 \\
\hline $\begin{array}{c}\text { Minimum heat output / } \\
\mathrm{kW}\end{array}$ & 52.3 \\
\hline $\begin{array}{c}\text { Minimum condensation } \\
\text { heat output / kW }\end{array}$ & 5.6 \\
\hline $\begin{array}{c}\text { Rated heating heat input / } \\
\mathrm{kW}\end{array}$ & 49.8 \\
\hline $\begin{array}{c}\text { Minimum heating heat } \\
\text { input / kW }\end{array}$ & 5.2 \\
\hline $\begin{array}{c}\text { Maximum heating } \\
\text { pressure / MPa }\end{array}$ & 0.3 \\
\hline
\end{tabular}

\section{Test data analysis}

As the system is in the trial operation stage, the gas wall mounted boiler has been installed but has not been debugged, and the heat storage tank cannot be foamed and insulated due to low ambient temperature, so both are not put into operation. The commissioning started on November 1, 2017, and the preliminary heating of the system relying on the solar flat collector as a single heat source was realized on December 6. The heating effect is ideal. The radiators in each room of the office building can reach the ideal temperature during the solar energy work, and the indoor temperature of the office building is maintained at $20{ }^{\circ} \mathrm{C}$ for about $7 \mathrm{~h}$ in the daytime (the data on December 30, 2017 are selected for analysis).

\subsection{Solar radiation}

The variation of solar radiation with time is shown in Figure 2. As can be seen from Figure 2, from 9:00 to 11:00, the solar radiation intensity increases sharply from $209 \mathrm{~W}$ $/ \mathrm{m}^{2}$ to $863 \mathrm{~W} / \mathrm{m}^{2}$, and the average daily solar radiation intensity lasts more than $800 \mathrm{~W} / \mathrm{m}^{2}$ for nearly 6 hours. 
Therefore, the unique solar radiation characteristics in Tibet provide conditions for the promotion of solar heating system with supplementary combustion in this area.

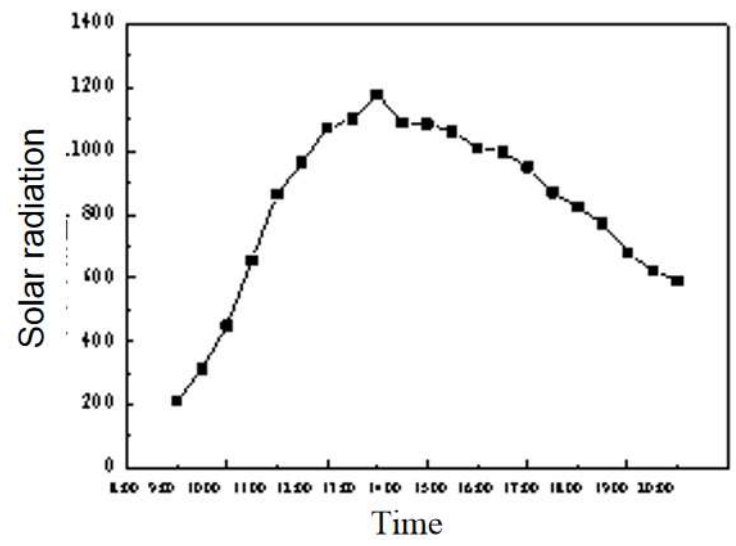

Fig. 2 Variation curve of solar radiation with time

\subsection{Indoor and outdoor temperature}

The ambient temperature has a great influence on the heat collection and heat loss of solar heating system. The changes of outdoor temperature and indoor temperature in the range of 9:00-19:00 are shown in Figure 3. Because the heat storage tank is not put into use, the change trend of indoor temperature and outdoor temperature is basically the same, and it is obviously affected by the change of outdoor temperature. If excess heat is stored, the indoor temperature change will be more stable and basically maintained in a narrow temperature range.

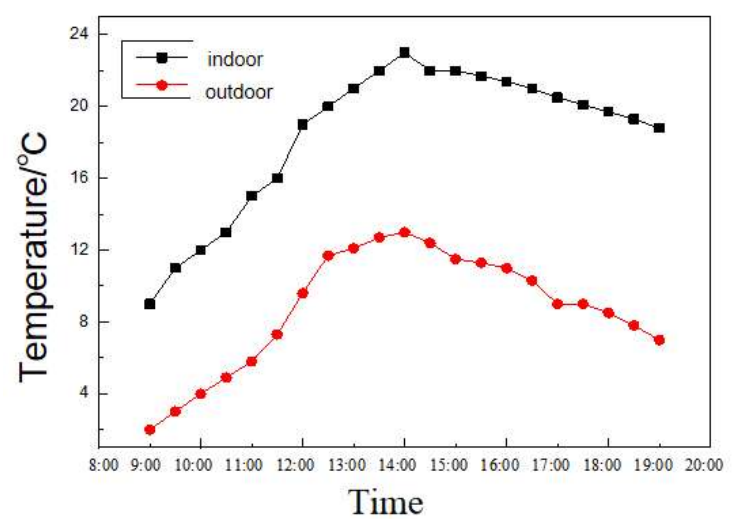

Fig. 3 Variation curve of indoor and outdoor temperature with time

\subsection{Inlet and outlet temperature of secondary network}

The variation curve of inlet and outlet temperature of secondary network with time is shown in Figure 4. During the test, the system only relies on solar energy as a single heat source for heating, so the inlet temperature of the secondary network rises slowly from 9:00 to 10:00, the temperature rises rapidly from 10:00 to $14: 00$ and reaches the highest value, and the temperature decreases slowly after 14:00. After 18:30, the secondary network will be used as a heat source to heat the primary network until the secondary network is used as the end again after 9:00 the next day to absorb heat from the primary network. Compared with Fig. 3, the change curve of the inlet and outlet temperature of the secondary network with time is basically consistent with the change trend of the solar radiation with time, indicating that the magnitude of the solar radiation directly affects the inlet and outlet temperature of the secondary network.

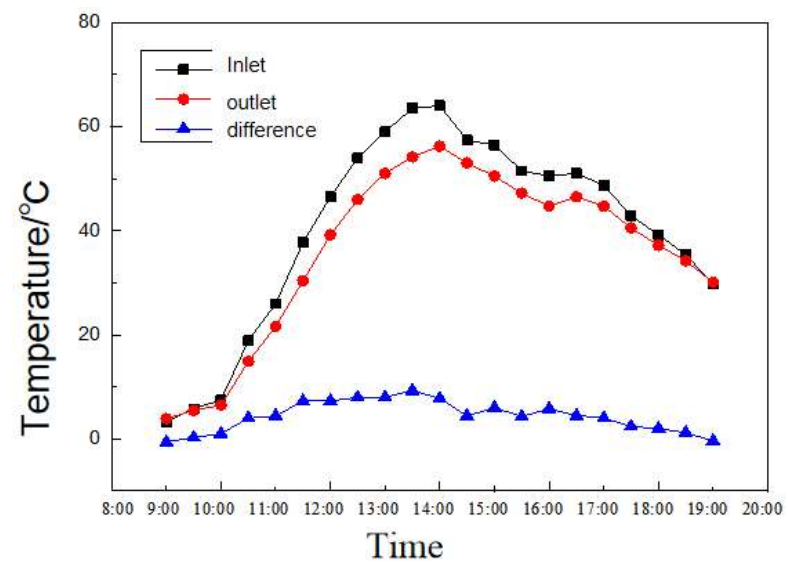

Fig. 4 Variation curve of inlet and outlet temperature of secondary network with time

\subsection{Inlet and outlet temperature of primary network}

The changes of inlet and outlet temperatures of primary network collector are shown in Figure 5. The inlet and outlet temperature of the collector is relatively high. The minimum temperature at the inlet of the collector is $3.7^{\circ} \mathrm{C}$ and the maximum temperature is $60{ }^{\circ} \mathrm{C}$; The minimum temperature at the collector outlet is $3.1{ }^{\circ} \mathrm{C}$, and the maximum temperature is $65.6^{\circ} \mathrm{C}$. The daily average values of the inlet and outlet temperatures of the collector are higher than the outdoor ambient temperature, indicating that the collector operates at high temperature and has great heat dissipation loss, which is not beneficial to increasing the heat collection efficiency. The temperature difference between the inlet and outlet of the collector is basically maintained above $4{ }^{\circ} \mathrm{C}$, and the maximum temperature difference is about $6.6^{\circ} \mathrm{C}$ at noon. The outlet temperature of the collector is higher than the inlet temperature after 9:00, indicating that the collector absorbs sunlight radiation in the daytime and the heat collection is positive. The temperature change trend of the medium at the inlet and outlet of the collector is the same. With time, it increases first and then decreases, reaching the maximum at about 14:00. At the same time, the change trend is that it increases rapidly before 14:00, and the temperature change is stable after 14:00. The temperature difference between the inlet and outlet of the collector remains basically unchanged during operation, and its operation is in good condition. 


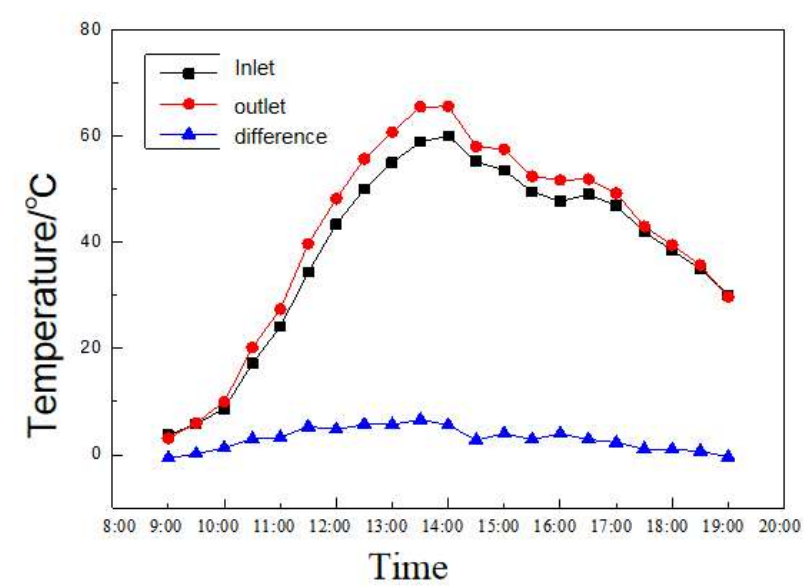

Fig. 5 Variation curve of inlet and outlet temperature of collector with time

\section{Conclusion}

a) According to the geographical location and solar irradiation characteristics of Tibet, the radiation absorbed by flat plate collector is measured by solar irradiator, and its variation trend with time is obtained. The results show that the solar radiation increases sharply from 9:00 to 11:00 every day, and reaches the maximum from 13:00 to 14:00. However, because the heat storage tank is not put into use, the indoor and outdoor temperature changes have the same trend, which is obviously affected by the outdoor temperature change.

b) Because the solar distributed heating system with supplementary combustion relies on solar energy as a single heat source for heating during the test, the secondary network is used as the heat source for heating the primary network after about 18:30; Until about 9:00 the next day, the secondary net is used as the end to absorb heat from the primary net. However, the system only provides heat for office buildings rather than residential buildings. If the weather is sunny, solar energy as a single heat source can meet the heating needs of users for most of the day.

\section{References}

1. Wang Dengjia, Liu Yanfeng, Wang Lijuan. Study on flow law of active solar heating water supply pipe [J]. Journal of solar energy, 2011 (9): 1387-1390.

2. CARPANETO E, LAZZERONI P, REPETTO M. Optimal integration of solar energy in a district heating network[J]. Renewable Energy, 2015 (75) : 714-721.

3. Liu lifeI, Luo Huilong, Tian Panyu, et al. Heat utilization analysis based on solar cogeneration [J]. Low temperature building technology, 2016 (11): 134-136.

4. Qu Shilin, sun Zhifeng, Ji Yubao, et al. Analysis and Experimental Research on the influence of heat storage tank on the performance characteristics of solar water source heat pump system [J]. Journal of solar energy, 2012, 33 (8): 1405-1410.
5. Meng Erlin, sun Zhigao, Liu Chenggang, et al. Experimental study on system performance of solar floor radiation system for night heating $[\mathrm{J}]$. Thermal science and technology, 2016,15 (2): 149-153.

6. LIU T, LI Z, HE G. Experiments of a Heat Pump Water Heating System Using Stored Solar Energy to Defrost [J]. Energy Procedia,2017 (105):1130 -1135.

7. Ling Deli, Li Ming, Luo Xi, et al. Study on drying characteristics of cut tobacco based on trough concentrating solar heating [J]. Journal of solar energy, 2015 (2): 460-466.

8. Guo song, Zheng Xin, Qiu Zejing, et al. Study on the performance of steam generation system using solar medium temperature heat collection [J]. Thermal science and technology, 2017,16 (2): 159-165.

9. ZHANG H, HONG H, GAO J, et al. Thermodynamic performance of a mid-temperature solar fuel system for cooling, heating and power generation[J]. Applied Thermal Engineering, 2016,106:1268-1281.

10. Chen Hongbing, Li Qiang, Chen Xilin, et al. Performance study of centralized solar water heating system [J]. Renewable energy, 2017, 35 (4): 613-620.

11. Xiangdong. Water saving, energy saving and environmental protection transformation of gas water heater [J]. Coal technology, 2011, 30 (10): 235-236.

12. Wang Xiaofeng, CIREN pingcuo, Wang junle. Some thoughts on the utilization of renewable energy in Tibet [J]. Tibet Science and technology, 2006 (8): 1316.

13. Wang Xinming. Solar heat pump central hot water system [J]. Tibet Science and technology, 2007 (9): 20-22.

14. KICSINY R. Transfer functions of solar heating systems with pipes for dynamic analysis and control design[J]. Solar Energy,2017 (150): 596-607.

15. Li Xinguo, Hu Xiaochen, Wang Jian. Energy analysis and experiment of solar energy, heat storage and ground source heat pump combined system [J]. Journal of solar energy, 2012 (4): 640-646.

16. Yang Wansheng, Li Lirong. Experimental study on sunshade solar phase change collector [J]. Renewable energy, 2015 (7): 965-970. 